\title{
Addressing Child Trafficking in South Asia
}

Romana Lepcha is working as a guest faculty at the Department of International Relations, Sikkim University.

\begin{abstract}
This paper discusses the different measures to address the problem of child trafficking in South Asia more efficiently that include establishment of new institutions and legal mechanisms and/or reform of the existing bilateral, multilateral, regional and international agreements. Issues of responses, cooperation, and coordination of law enforcement officials to address child trafficking are also included in this paper. Prevention, protection and prosecution measures such as rehabilitation programmes, better data, strategy and reporting to enhance anti trafficking efforts, strengthen the capacity of officials in the law enforcement agencies, immigration, education, social welfare, labour and other relevant departments to prevent child trafficking are also discussed in detail in this paper.
\end{abstract}

Keywords: Trafficking, Child Trafficking, South Asia, Migration, Criminal Justice.

Definitions of trafficking have varied across countries and laws. However, the definition provided by the United Nation Protocol to Prevent, Suppress and Punish Trafficking in Persons, Especially Women and Children is generally accepted internationally.

It states:

Trafficking in persons' shall mean the recruitment, transportation, transfer, harbouring or receipt of persons, by means of threat or use of force or other forms of coercion, of abduction, of fraud, of deception, of the abuse of power or of a position of vulnerability or of the giving 
Salesian Journal of Humanities and Social Sciences, Vol. X, No. 1. (May 2019)

ISSN: 0976-1861 | DOI: 10.51818/SJHSS.10.2019.24-34 | Page: 24-34,

Section: Article

or receiving of payments or benefits to achieve the consent of a person having control over another person, for the purpose of exploitation. ${ }^{1}$

This is the first internationally accepted definition on trafficking and the Protocol came into force on 25 December 2003. The most important characteristics of this is, it provides protection to victims of trafficking from prosecution for the acts they are forced into, and talks explicitly over preventive measures, victim compensation, repatriation, etc. ${ }^{2}$

United Nations Children's Fund (UNICEF) defined trafficking of children as, 'any person under 18 who is recruited, transported, transferred, harboured or received for the purpose of exploitation, either within or outside a country' ${ }^{3}$ Protection of child is an issue in every country and a high priority for UNICEF. The vision and approach of UNICEF is to prevent and protect children from violence, exploitation and abuse and to ensure children's rights to survival, development and well being.

Human trafficking means illegal trade of human beings for the purposes of slavery, forced and bonded labour, child labour and above all commercial sexual exploitation. Among the various forms of human trafficking like sex trafficking, labour trafficking, organ transplantation, etc, child trafficking is the most common form which is a global phenomenon. Child trafficking is an extreme form of human rights violation as it denies the fundamental rights of mobility, freedom and dignity of the children.

Trafficking of children violates children's rights and infringes upon the child's physical and mental integrity which is central to

\footnotetext{
${ }^{1} \mathrm{U}$ N, "Protocol to Prevent, Suppress and Punish Trafficking in Persons, Especially Women and Children, Supplementing the United Nations Convention against Transnational Organized Crime", United Nations, accessed November 25, 2012, www.uncjin.org/Documents/.../final.../convention_\%20traff_eng.pdf.

${ }^{2}$ B. Ghosh, "Trafficking in Women and children in India: Nature, Dimensions and Strategies for Prevention", The International Journal of Human Rights, no.13 (2009): 716-738.

${ }^{3}$ Inter-Paramilitary Union UNICEF 2005, “Combating Child Trafficking, Handbook for Parliament", www.unicef.org/ceecis/IPU_combattingchildtrafficking_GB.pdf.
} 


\section{6 / Romana Lepcha}

Salesian Journal of Humanities and Social Sciences, Vol. X, No. 1. (May 2019) ISSN: 0976-1861 | DOI: 10.51818/SJHSS.10.2019.24-34 | Page: 24-34,

Section: Article

the experience of human dignity, and poses a significant threat to the child's life. ${ }^{4}$ Children are trafficked in South Asia for various purposes in which sexual exploitation is the primary goal. Child labour is a form of work that is likely to be hazardous to the physical and mental health, moral and social development of children and can also hamper their education. ${ }^{5}$ Other purpose for exploitation includes agricultural labour, factory works, domestic servitude, organs trade, child pornography, begging and other related criminal activities. Boys from Bangladesh and Pakistan have been trafficked to work jockeys in camel racing in the Middle Eastern countries. ${ }^{6}$ Trafficking for forced or arranged marriage is another critical issue in Afghanistan and Bangladesh where children are the major victims. ${ }^{7}$ Debt release, dispute settlement and forced military recruitment are other causes of trafficking of children. ${ }^{8}$

The main international documents dealing with the trafficking of children are The Child Labour (Prohibition and Regulation) Act, 1986; UN Convention on the Rights of the Child, 1989; the ILO Worst Forms of Child Labour Convention, 1999 and the U.N Protocol to Prevent, Suppress and Punish Trafficking in Persons, especially Women and Children, 2000.

\section{Trends and Patterns of Child Trafficking in South Asia}

In South Asia, cross border trafficking or movement of persons within and outside the countries for exploitation in various forms is a big problem. Among these, Child trafficking is an issue that is extremely prevalent in South Asia and is continuing to grow rapidly. Economic injustice like poverty, unemployment, social inequality based on gender, caste, race, ethnicity, forced/early marriage and

\footnotetext{
${ }^{4}$ Inter-Paramilitary Union 2008, "South Asia in Action: Preventing and Responding to Child Trafficking", accessed July 8, 2015, www.unicef-irc.org/publications/.

${ }^{5}$ P. Bhoi, "Social Dimensions of Child Labour", Dialogue, (2005) vol. 7, no. 1: 119125.

${ }^{6}$ South Asian March Against Child Trafficking 2013, “Global March Against Child Labour", www.globalmarch.org/issues/Child-Trafficking

${ }^{7}$ Ibid.

${ }^{8}$ Inter-Paramilitary Union 2008.
} 
patriarchal social system, insufficient existing laws or lack of law enforcement, corruption, civil war or other internal unrest, natural calamities like earthquake are some noteworthy factors that cause/ intensify child trafficking in South Asia.

According to the US State of Department, approximately 600,000 to 800,000 people are trafficked every year across international borders, and up to $50 \%$ of these are children. In India specifically, it is estimated that around 135,000 children are trafficked each year. National Human rights Commission of India found that India is becoming a source, transit point and destination for traffickers of women and children for the purpose of exploitation.

It is estimated by Maiti Nepal, an NGO of Nepal that between 5000 to 7000 Nepalese girls are trafficked every year to India and most of them are barely 9-10 years old and 200,000 to over 250,000 Nepalese women and girl child are already in Indian brothels. ${ }^{9}$

\section{Measures/Ways to Address Child Trafficking in South Asia}

\section{Re-define the term 'Trafficking'}

While there are a number of international instruments dealing with human trafficking, the primary tool used by the Governments of South Asian nations to combat human trafficking is their own domestic laws. However, those existing domestic laws of South Asian nations focus only on the portion of trafficking that is for the purpose of prostitution. None of the existing trafficking laws in these countries address trafficking in a holistic manner. By emphasizing the endpoint, the violence and abuse of human rights that occur during the process of trafficking and for purposes other than prostitution are not addressed. Domestic laws of all the nations lack collective understanding of trafficking. For example, India has specific law on trafficking ITPA, that does not define trafficking as a whole, but defines trafficking as sexual exploitation. ${ }^{10}$

${ }_{9}^{9}$ Maiti Nepal, “Annual Report 2016", https://maitinepal.org/admin/.../Maiti_ Nepal_Annual_Report_2016.pdf.

10 UNODC (2011), "Responses to Human Trafficking in Bangladesh, India, Nepal and Sri Lanka", accessed August 3, 2011, www.unodc.org/.../human- 


\section{8 / Romana Lepcha}

Salesian Journal of Humanities and Social Sciences, Vol. X, No. 1. (May 2019) ISSN: 0976-1861 | DOI: 10.51818/SJHSS.10.2019.24-34 | Page: 24-34,

Section: Article

The existing laws have not been properly defined and there are several loopholes ${ }^{11}$ in them due to which the perpetrators of trafficking escape from being effectively punished. The UN Trafficking Protocol is an international legal framework to fight transnational organized crime with a detailed agreement on tackling trafficking in persons.

One of the major loopholes in tackling the menace of human trafficking in SAARC countries is the very definition provided in the SAARC Convention on Combating the Crime of Trafficking in Women and Children for Prostitution, 2002, which is very narrow and limited only to 'prostitution'. ${ }^{12}$ The end purposes of trafficking are not limited to sexual exploitation alone but are as varied as the potential for profit where women, men, and children are trafficked for the purpose of forced labour, child labour, forced marriage, illegal recruitment, debt bondage, exploitation of labour, involvement in organized crime, organ transplant etc. Hence the title of the SAARC Convention should be expanded to include the above as well.

The legal definition of trafficking of each states of South Asia should also be revised according to the definition provided by UN Protocol to Prevent, Suppress, and Punish Trafficking in Persons, 2000, as it has provided a detailed guidelines and provisions for punishment for human trafficking in general and child trafficking in particular. ${ }^{13}$ Re-examining of current laws of all the States in the trafficking/.../Resources_to_Human..._T...

${ }^{11}$ The existing laws only emphasise on sexual exploitation as one and only form of trafficking. Laws related to trafficking exist on paper but lack implementation. The procedure of rehabilitation as well as reintegration of trafficking victims need to be incorporated into the existing laws.

12 The person subject to trafficking means "Women and Children victimized or forced into prostitution by the traffickers by deception, threat, coercion, kidnapping, sale, fraudulent marriage, child marriage or any other unlawful means" (SAARC Convention on Combating the Crime of Trafficking in Women and Children for Prostitution, 2002).

13 "As per this definition human trafficking is an exploitation which includes, at a minimum, the exploitation of others through prostitution or other forms of sexual exploitation, forced labour or services, slavery or practices similar to slavery, servitude or the removal of organs" (UN Protocol to Prevent, Suppress, and Punish Trafficking in Persons, 2000). 
light of internationally accepted definition may cover all aspects of human trafficking/child trafficking and control such business. An effective provision for additional penalties should apply to persons including perpetrators and public officials found guilty of trafficking.

\section{Reform Criminal Justice System and Procedures}

Corruption is prevalent in the criminal justice system in South Asia. As a result, traffickers use corruption to extend their operations and avoid persecution. At times, the law enforcement agencies are also partners and parties in the crime of trafficking. The police, border control authorities, immigration services, security/armed forces, public officials, private sector actors such as travel agencies, transportation sectors, financial institutions, etc., are among the partners in the crime. However, lack of knowledge and commitment at this level can be equally serious leading to poor prosecutorial systems, failure to adequately utilize and protect witnesses, failure to apply trial prosecutorial briefs, failure to adequately utilize and protect witnesses, failure to apply trail procedures properly, and inappropriate sentencing. ${ }^{14}$ Due to all these, the present legal framework to combat human trafficking results in re-victimisation of the victims of exploitation while the exploiters remain mostly unpunished. Corrupt practices within legal frameworks and judicial weaknesses have great impact on the victims of trafficking who suffer a lot. Their cases are lost or badly dealt in most of the situations.

To combat child trafficking, all the governments should give priority to investigate and take legal action against corrupt officials. There should be a life imprisonment if the perpetrator of the crime is a law enforcement official. The UN Convention against Transnational Organized Crime recommends effective action in the prevention, detection, and punishment of corrupt public officials. ${ }^{15}$

14 Anne T. Gallagher, The International Law of Human Trafficking, (New York: Cambridge Press, 2010).

${ }^{15}$ UN, General Assembly Resolution 55/25 of 15 November 2000, United Nations Convention against Transnational Organized Crime and the Protocols Thereto, 


\section{0 / Romana Lepcha}

Salesian Journal of Humanities and Social Sciences, Vol. X, No. 1. (May 2019) ISSN: 0976-1861 | DOI: 10.51818/SJHSS.10.2019.24-34 | Page: 24-34,

Section: Article

For the improvement in law enforcement, all the states should establish a centralized group of specialist prosecutors to handle issue of corruption in trafficking cases and to provide other post-rescue support to the victims. This group should jointly address issue of corruption in trafficking by sharing information and resources that may help to speed-up investigation process. Specific anti-trafficking training needs to be delivered to the committed prosecutors who may contribute to tackle child trafficking issue and eliminate practice of corruption within law enforcement agencies and encourage them to perform effectively. It will help to strengthen cross-border legal cooperation between the states.

\section{Effective Investigation Process by Law Enforcement Agencies}

There is a lack of commitment when it comes to the investigation of child trafficking. Both in India and Nepal, law enforcement officials receive poor basic training or poor basic investigation skills. There are also no clear training and development plans designed and exercised to develop the knowledge and skills of these officials. In South Asia, the external sources like INGOs/NGOs provide training and development opportunities to law enforcement agencies to prepare them for their task as trafficking investigators. ${ }^{16}$ Thus, an effective and efficient measure is possible for law enforcement

2004, Article 8: 1: “Each State Party shall adopt such legislative and other measures as may be necessary to establish as criminal offences, when committed intentionally: (a) The promise, offering or giving to a public official, directly or indirectly, of an undue advantage, for the official himself or herself or another person or entity, in order that the official act or refrain from acting in the exercise of his or her official duties; (b) The solicitation or acceptance by a public official, directly or indirectly, of an undue advantage, for the official himself or herself or another person or entity, in order that the official act or refrain from acting in the exercise of his or her official duties. Article 9 (2): Each State Party shall take measures to ensure effective action by its authorities in the prevention, detection and punishment of the corruption of public officials, including providing such authorities with adequate independence to deter the exertion of inappropriate influence on their actions". U N 2000, "Protocol to Prevent, Suppress and Punish Trafficking in Persons, Especially Women and Children, Supplementing the United Nations Convention against Transnational Organized Crime, United Nations", accessed November 25, 2012. www.uncjin.org/Documents/.../final.../convention_\%20traff_eng.pdf.

${ }^{16}$ UNODC 2008, Resource Book on the Legal Framework on Anti Human Trafficking, (New Delhi, India: Regional Office for South Asia). 
agencies if states work in collaboration with such organisations. More so, efforts by such organisation to raise public awareness will help in interception of child trafficking victims in the border areas.

An effective investigation response is possible when there is an equal participation of all levels of society, from law enforcement prosecutors/officials to NGOs to immigration officials to local communities. Human trafficking or child trafficking is a sensitive crime, so investigation process requires careful treatment of victims and their witnesses.

\section{Effective Border Control}

Due to open and porous border specially between India and Nepal, trafficking of women and children has become one of the easiest and less risky crimes compared to drugs and arms trafficking from Nepal to India. A number of women and children are trafficked to Indian brothels because of open and unregulated national border between Nepal and India. There is absence of proper law enforcement mechanism between Nepal and India for border control personals to protect and prevent individual from trafficking, especially women and children.

Therefore, there should be strict action on regulating the movement of population on either side of Nepal and India. Both the States should look into the measures that provide employment opportunities to their citizens in their respective territories to avoid illegal immigration. Along with this, an intensive research, joint reviews or initiatives, successful exchange of ideas on the diverse aspects of open border between India and Nepal would check and regulate illegal activities like human trafficking or child trafficking occurring at the border.

There is a need of cross-border cooperation between India and Nepal, especially between law enforcement agencies to investigate and prosecute the recruiters and the transporters involved in trafficking of persons. There are very few genuine investigations that have been made in India and Nepal to track traffickers 


\section{2/Romana Lepcha}

Salesian Journal of Humanities and Social Sciences, Vol. X, No. 1. (May 2019) ISSN: 0976-1861 | DOI: 10.51818/SJHSS.10.2019.24-34 | Page: 24-34,

Section: Article

and most of these have been initiated by non-governmental organizations with the help of concerned department. ${ }^{17}$ Cross border cooperation has significantly contributed to breaking down various criminal networks like transnational trafficking of persons or other transnational crimes like drugs and arms trafficking. The strengthening of Indo-Nepal border controls to fight trafficking, to criminalize all forms of trafficking and to prosecute and punish traffickers. Cross border collaboration and coordination between countries should aim to ensure that there are no safe havens for traffickers. The legal framework in both States must ensure punishment of traffickers by conducting effective investigation and eliminating the proceeds of trafficking with effective judicial cooperation.

\section{Addressing Illegal Migration to Curb Trafficking}

The process of migration in the name of foreign employment in many cases is directly or indirectly linked to trafficking. Illegal migration contributes to an environment of vulnerability and abuse where anyone can become a victim of trafficking. As illegal migrants are highly vulnerable to being trafficked due to a range of factors like lack of legal status or protection, limited language skills, limited employment options, poverty and immigration related debts, and other socio-economic conditions.

Illegal/undocumented migration canbeonereason for continuous increase in child trafficking in the name of foreign employment. For instance, according to the chairperson of Maiti Nepal, in Nepal, a 15 years old girl was found to have a passport which showed that she was 30 years of age. In this matter, the existing laws related to trafficking, foreign employment, migration etc. should focus or address those problems to control human trafficking or child trafficking in the name of foreign employment. Government, with other law enforcement agencies, NGOs, institutions etc., should

${ }^{17}$ For e.g. NGOs like Kanchenjunga Uddhar Kendra (India) and Maiti Nepal (Nepal) have been generously working with this border issue. They are making efforts to rescue victims from railway stations, bus stations and other places. They also provide awareness on safe migration to individuals who cross border. 
work together to eliminate the dark side of foreign employment related human trafficking.

In short, a comprehensive and collective strategy is needed to combat human trafficking with a better enforcement of immigration laws and greater cooperation between law enforcement agencies of both the countries.

\section{Reforms in Rescue, Rehabilitation and Reintegration}

Special and enhanced measures should also be put in place to provide safety, support and assistance to child victims and to protect their privacy during their stay in the country of destination and throughout repatriation. ${ }^{18}$ Protection of Children's right as a measure against child trafficking, violence, exploitation and abuse should be developed by both the States and made operational at national and local levels. ${ }^{19}$ These measures include empowering children and youth by raising awareness on the risk of trafficking as well as its legal and policy framework to combat such a crime. Rescued child victims should be provided with child-friendly legal, medical and psychosocial services with proper reintegration programmes. Systematic collection of data and monitoring is also needed to control the magnitude of child trafficking.

Special support to victims as witness should be provided by the law enforcement agencies, as victims have a critical role to play in the criminal prosecution of traffickers. It will be difficult or impossible to investigate and prosecute without the cooperation and testimony of victims. It is a fact that victims of trafficking are often unwilling to cooperate with criminal investigations for fear of harm to themselves or their families. In such situations, the State or concerned department or law enforcement officials should do all within its power and resources to provide or otherwise ensure effective protection to victims who are cooperating in criminal investigations. ${ }^{20}$ Victims should also be provided with adequate

${ }^{18}$ UN Trafficking Protocol 2000, Art. 6.

${ }^{19}$ UNICEF, 2008.

${ }^{20}$ UN Organized Crime Convention 2000, Art. 24. 


\section{4 / Romana Lepcha}

Salesian Journal of Humanities and Social Sciences, Vol. X, No. 1. (May 2019) ISSN: 0976-1861 | DOI: 10.51818/SJHSS.10.2019.24-34 | Page: 24-34,

Section: Article

levels of support, assistance and information for the duration of their involvement in criminal proceedings. They should not be repatriated until after the completion of relevant legal proceedings and after they have been able to claim and receive compensation or other remedies. ${ }^{21}$

\section{Collaboration and Cooperation among Institutions}

The coordination between institutions such as the Ministry of Women and Child Development (MWCD), Ministry of Home Affairs (MHA), National Human Rights Commission (NHRC), National Commission for Women (NCW), Anti Human Trafficking Units etc. of the entire nation is needed.

\section{Conclusion}

While it is clear that each nation of South Asia has made enormous progress towards addressing child trafficking, the region still does not comply with international standards and much still needs to be done to tackle the problem of child trafficking. Effective regional and domestic measures should be created with protective environment where girls and boys are free from violence, exploitation, and unnecessary separation from family. There should be laws, services, behaviours and practices that minimize children's vulnerability, address known risk factors, and strengthen children's own resilience.

${ }^{21}$ UN Trafficking Protocol, 2000, Art 8. 